\title{
giFORSETI
}

\section{La motivación de la prueba en el arbitraje local: Énfasis en arbitrajes de construcción y la aplicación del artículo 1332 del Código Civil}

\author{
Juan Manuel Loza*
}

Resumen. - La motivación de las decisiones probatorias en arbitraje es un tema poco tratado en la doctrina y que merece una especial atención al momento de la emisión de laudos. Salvo pacto en contrario, los arbitrajes de derecho con materias complejas requieren de una sofisticada valoración de las pruebas y un dominio de reglas esenciales de teoría probatoria que garanticen a las partes una decisión justa y razonable en términos de lo debatido jurídica y técnicamente. Antes que una visión general de la motivación de los laudos, es imprescindible aterrizar en cómo se justifican racionalmente las decisiones sobre las pruebas relevantes en arbitraje.

\begin{abstract}
The motivation of the probative decisions in arbitration is a topic that is not very much treated in the doctrine and that deserves special attention at the moment of the issuance of awards. Unless otherwise agreed, the arbitrations of law with complex matters require a sophisticated valuation of the evidence and a mastery of essential rules of probative theory that guarantee the parties a fair and reasonable decision in terms of what is legally and technically debated. Before an overview of the motivation of the awards, it is imperative to land on how decisions are rationally justified on the relevant evidence that is acted in arbitration.
\end{abstract}

Palabras claves. - Arbitraje - Construcción - Proyectos - Prueba Técnica - Prueba Científica - Teoría Probatoria - Laudos.

Keywords. - Arbitration - Construction - Projects - Technical Test - Scientific Test Evidentiary Theory - Awards.

* Socio fundador de la firma Loza Legal. Desempeña su función en el área de Arbitraje y Derecho de la Construcción. Abogado por la Facultad de Derecho de la Universidad de Lima. Es parte de la Asociación Latinoamericana de Derecho de la Construcción. 


\section{Introducción}

El arbitraje se ha convertido en un mecanismo poderoso y eficiente de solución de controversias ${ }^{1}$. La doctrina aún no es del todo pacífica en considerar que el arbitraje fue la primera manifestación de lo que contemporáneamente conocemos como proceso ${ }^{2}$. Lo que sí es claro desde la Roma Clásica es que la decisión del llamado árbitro compromisario siempre anheló ser particularmente respetada y acatada en sus propios términos ${ }^{3}$.

En la actualidad, un laudo dista de ser venerado -y no lo tiene que ser- pues las partes persiguen intereses contrapuestos y cada una desea salir victoriosa en la tesis de caso que propone ante un Tribunal. Sin embargo, en el Perú la proliferación del mal llamado "recurso de anulación de laudo" constituye, en su gran mayoría, un abuso procesal y una manifestación de mala fe, gatillada por la consabida alegación de los "defectos de motivación": un constructo jurídico en nuestro medio.

Es así que la motivación del laudo se ha convertido en uno de los temas capitales del debate arbitral. Existen legislaciones en las que se faculta el pacto de no motivación entre las partes, en otras en las que se prescinde totalmente de la obligación de motivar el laudo ${ }^{4}$. Inclusive, en algunos reglamentos se deja a criterio del árbitro el acto de motivar $\mathrm{o} \mathrm{no}^{5}$, hasta en algunos casos las partes consiguen pactar el nivel de profundización de la motivación del laudo sobre la base de la autonomía de la voluntad propia del arbitraje.

1 Al margen de las normales discusiones, como por ejemplo, las que se generan en torno a la utilización de reglas transnacionales, lex mercatoria y arbitajes en materia de comercio internacional. Véase: GAILLARD, Emmanuel. El orden jurídico arbitral. Bogotá: Grupo editorial Ibañez, 2015, pp. 34 y ss. En ese mismo sentido: CALLUF FILHO, Emir. Arbitragem Internacional. O local da arbitragem. Curitiba: Jurua editora, 2006, pp. 74 y ss.

2 "El más afamado de los discípulos de Wlassak, Leopold Wenger, ya no seguía en este punto a su maestro, y el distanciamiento de esa teoría por parte de la romanística posterior ha sido ya prácticamente general. Baste mencionar, por remitir sólo a algunos de los más eminentes especialistas vivos en el ámbito del derecho procesal que se han pronunciado de forma expresa en contra del origen arbitral del procedimiento privado, los nombres de G. Pugliese, M. Kaser, A. Biscardi, M. Talamanca o B. Albanese. La pretendida génesis arbitral del proceso se aviene mal asimismo con las nuevas perspectivas sobre los orígenes del proceso privado abiertas en los últimos años por un importante sector de la doctrina italiana encabezado por R. Santoro, G. Nicosia y C.A. Cannata".

PARICIO, Javier. Los arbitrajes privados en la Roma Clásica. Madrid: Marcial Pons, 2014, p. 68.

3 Ulpiano, sostenía que se debía estar a la sentencia del árbitro compromisario, sea justa o injusta. El mismo Ulpiano refiere un rescripto de Antonio Pío, según el cual: “Debes soportar con buen ánimo incluso la sentencia menos probable, la más absurda o la más injusta".

4 En algunas legislaciones se aprecia un silencio absoluto en torno a la obligación de motivar el laudo. Por ejemplo, Uniform Arbitration Act no contiene una regulación específica sobre tal obligación. De hecho, el mismo Tribunal Supremo de Estados Unidos ha emitido jurisprudencia en la que establece que los árbitros no están obligados a motivar los laudos.

5 “Commercial Arbitration Rules - American Arbitration Association. R-46. Form of Award: (...)

(b) The arbitrator need not render a reasoned award unless the parties request such an award in writing prior to appointment of the arbitrator or unless the arbitrator determines that a reasoned award is appropriate." 
Sin embargo, hay algo que está detrás de la motivación del laudo y que muchas veces pasa desapercibido: la motivación de la prueba ${ }^{6}$.

Según Wróblewsy7, la racionalidad de la decisión probatoria debe ser controlada y ese control se proyecta sobre las razones que fundamentan la libre convicción del juzgador expresadas en la motivación. Bajo un criterio analítico, tal racionalidad podrá obtenerse si se transita primero por una valoración singularizada de las pruebas y luego por una valoración conjunta de ellas.

En arbitraje, doctrina mayoritaria reconoce que la motivación del laudo debe ser flexible, breve, centrándose en aspectos claves de la controversia8, siempre dentro de un marco de razonabilidad ${ }^{9}$. Por ello, como refiere Canals ${ }^{10}$, es polémica la doctrina de la equivalencia entre la motivación de laudos y sentencias. De ahí que ejercer control de motivación sobre un laudo no es lo mismo que hacerlo sobre una sentencia. Sin embargo, la pregunta que se decanta es la siguiente: ¿los árbitros deben aplicar las reglas convencionales de teoría probatoria o estas quedan supeditadas a la flexibilidad y discrecionalidad? Y, entonces, ¿cuáles son los límites? No es una cuestión baladí, pues la motivación del laudo está íntimamente vinculada a cómo se han valorado las pruebas y a cómo se ha decidido respecto de ellas.

En sede nacional continúa el debate en torno a la motivación del laudo y al "estándar aplicable". Sobre el particular existen dos corrientes claramente

6 GASCÓN ABELLÁN, Marina. Cuestiones probatorias. Bogotá: Universidad Externado de Colombia, 2012, pp. 175 y ss.

7 WRÓBLEWSKI, Jerzy. La prueba jurídica: axiología, lógica y argumentación. San Sebastián: Universidad del país Vasco, 1989, p. 186.

8 Sin lugar a duda uno de los principales impulsores del arbitraje a nivel mundial es el profesor Gary Born, cuya especial forma de explicar las bondades del arbitraje calan profundamente en los países donde se práctica correctamente este mecanismo de solución de controversias. Este autor pone especial interés en remarcar lo importante que significa flexibilizar la motivación del laudo y hacerlo dinámico.

BORN, Gary. International Commercial Arbitration: Commentary and Materials. New York: Transnational Publishers, pp. 110 y ss.

9 “El arbitraje debe guardar diferencias constructivas con los procedimientos judiciales, que no lo hacen mejor ni peor que éstos, pero sí -por esencia- distinto. La flexibilidad no puede, claro, conducir a un desorden ni a consecuencias que no sean comprensibles por el discurrir del entendimiento. Todo arbitraje debe guardar un balance y equilibrio entre las partes, de manera que alguien que analice una decisión arbitral, si es una persona con apreciación razonable, pueda entender su contenido u objeto, su causa, y su fin. En el arbitraje, las formas no deben considerarse fines en sí mismas. Esa misma flexibilidad tiene consecuencias en lo sustantivo. Los árbitros deben prestar atención y analizar las fuentes sustantivas del derecho, incluyendo las decisiones o precedentes judiciales relevantes y persuasivas. No deben ignorarlas so pretexto de autonomía. No obstante, los árbitros deben tener un margen de actuación o discreción sustantiva para realizar interpretaciones y aplicaciones del derecho. Deben ser rigurosos y profundos en sus métodos y técnicas de análisis, pero no rígidos ni exégetas estrictos".

DÍAZ-CANDIA, Hernando. "Tendencias actuales del arbitraje en Latinoamérica. Arbitraje". Consulta realizada el día 21 de julio de 2020. Disponible en: https://arbitrajeraci.files.wordpress.com/2018/07/tendencias-actuales-del-arbitraje-enlatinoamc3a9rica.pdf

10 CANALS VAQUER, Roger. "La falta de motivación del laudo como motivo de su impugnacio $\square$ n por infracción del orden público". Consulta realizada el día 21 de julio de 2020. Disponible en: https://arbitrajeraci.files.wordpress.com/2018/08/11-02-10.pdf 
identificables: una primera partidaria de la flexibilidad de la motivación ${ }^{11} ; \mathrm{y}$, en la otra vereda, una posición que exige una decisión justificativa más elaborada12.

Frente a ese debate, lo razonable es encontrar un balance y establecer criterios de buen proceder bajo las pautas del razonamiento jurídico.

En tal sentido, consideramos que el rigor básico de motivación exigible a los árbitros podría seguir la siguiente lógica, minimum minimorum:

“Ciertamente, la mayoría de los sistemas requieren que el laudo contenga una referencia a tales circunstancias fácticas, pero la motivación del laudo en cuanto a los hechos exige algo más que una mera referencia a los hechos. Implica que el laudo debe reseñar los hechos que han sido probados y que se vinculan a los fundamentos jurídicos, y debe existir asimismo un mínimo principio de valoración de la prueba o, si se quiere, de justificación de por qué el árbitro considera dichos hechos como probados. La ausencia de revisión de fondo del laudo no permite poner en cuestión la valoración de la prueba por el árbitro, a menos que resulte abiertamente irracional o arbitraria. Pero las partes tienen derecho a conocer qué hechos consideran los árbitros como probados y por qué. Solamente así quedará garantizado el ejercicio de sus derechos de defensa $y$, en particular, la posibilidad de articular un recurso o la oposición al reconocimiento y ejecución del laudo. En suma, el principio de motivación del laudo se extiende por igual a los hechos y al Derecho, a menos que, como ocurre con la legislación rusa, la propia normativa limite dicha motivación, estrictamente, a los fundamentos sustantivos del laudo ${ }^{13}$.

Y es que, bien vistas las cosas, no se es menos flexible y tampoco más garantista si los árbitros mantienen un esfuerzo básico de valoración probatoria y de justificación decisoria a plasmarse en el laudo. Consideramos que la labor probatoria de las partes y sus argumentaciones, en sus aspectos centrales, es decir, los que sellan la materia controvertida, deben estar capitalizadas en el laudo. Como sostiene Corchuelo14, el defecto fáctico se presenta cuando los árbitros dejan de decretar, practicar o valorar una prueba pertinente $\mathrm{y}$ determinante para la decisión de fondo.

Siendo así, lejos de propiciar un debate lleno de abstracciones, a veces alejado de la práctica, el tema del estándar de motivación de laudos en arbitraje doméstico

11 En esta corriente se acepta como válido que el laudo pueda no ser tan estricto en cuestiones de valoración probatoria pormenorizada y de las justificaciones que deban exponerse en el arribo de la decisión. Se invoca, en respaldo de esta posición, legislación comparada que concede amplios márgenes de flexibilidad a la motivación; $\mathrm{y}$, en algunos casos, la prescindencia de la obligación de motivar.

12 En esta corriente se suelen equiparar algunas exigencias de motivación judicial al ámbito del arbitraje, aunque con algunos matices. El hecho es que esta posición es tendiente a vincular al arbitraje con las garantías constitucionales del proceso.

13 SÁNCHEZ LORENZO, Sixto. “Un análisis comparado de la motivación del laudo en el arbitraje comercial internacional". Consulta realizada el día 21 de julio de 2020. Disponible en: https:/ /arbitrajeraci.files.wordpress.com/2018/12/11.3.01.pdf

14 CORCHUELO URIBE, Daniela. Anulación de laudos arbitrales por errores sustanciales en Colombia. Bogotá: Universidad Externado de Colombia, 2013, p. 59. 
nos obliga a repasar algunas circunstancias a fin de mejorar las buenas prácticas en el derecho arbitral peruano.

En esa tarea, traer a colación la importancia de la motivación de la prueba (especie) como manifestación de la garantía de la motivación de las decisiones (género), desde nuestro punto de vista resulta trascendente.

\section{II. ¿Qué es la motivación de la prueba y cómo funciona en el arbitraje nacional?}

\section{i. Premisas esenciales: La fractalidad del arbitraje}

La obligación de motivar las decisiones encuentra su fundamento en el artículo 139 inciso 5 de la Constitución Polìtica del Perú, y en lo que concierne a la motivación en el arbitraje, el Decreto Legislativo 1071 -norma que regula el arbitraje en el Perú- regula la motivación exigible a los árbitros en los artículos $43^{15}$ y $56^{16}$.

En los últimos años, se ha venido cuestionando el rol de la justicia comercial en los procesos de impugnación de laudo ${ }^{17}$. Según un sector de la doctrina, como por ejemplo Cantuarias y Repetto18, la anulación de laudos basada en 'errores' de motivación afecta a la propia institución arbitral y a su independencia, siendo este un intervencionismo judicial intolerable que nos aleja de los altos estándares arbitrales.

En esa línea de pensamiento, abundan estudios sobre el correcto encuadramiento de la motivación en el arbitraje y su necesaria diferenciación con la motivación en sede judicial.

A nuestro ver, no hay duda de que, existen diferencias entre motivar un laudo y una sentencia. Lo que ha venido ocurriendo es que, en ocasiones, se confunde la elasticidad o flexibilidad que brinda el arbitraje con una inadecuada motivación

15 "Artículo 43.- Pruebas

1. El tribunal arbitral tiene la facultad para determinar de manera exclusiva la admisión, pertinencia, actuación y valor de las pruebas y para ordenar en cualquier momento la presentación o la actuación de las pruebas que estime necesarios.

2. El tribunal arbitral está facultado asimismo para prescindir motivadamente de las pruebas ofrecidas y no actuadas, según las circunstancias del caso".

16 "Artículo 56.- Contenido del laudo

1. Todo laudo deberá ser motivado, a menos que las partes hayan convenido algo distinto o que se trate de un laudo pronunciado en los términos convenidos por las partes conforme al artículo 50. Constarán en el laudo la fecha en que ha sido dictado y el lugar del arbitraje determinado de conformidad con el numeral 1 del artículo 35. El laudo se considera dictado en ese lugar".

17 Como dato histórico de los procesos de impugnación arbitral, es interesante mencionar que en la Roma Clásica no hubo propiamente impugnación interna. Existió la exceptio doli que generaba un nuevo proceso donde se anulaba la sentencia. El proceso se seguía ante un iudex elegido por las partes y sólo por la elección se decía que el proceso era arbitral.

18 CANTUARIAS SALAVERRY, Fernando y REPETTO DEVILLE, José Luis. “El nuevo potro indomable: el problemático estándar de motivación de los laudos exigido por las cortes peruanas". En Ius et Veritas, núm. 51, 2015, pp. 41 y ss. 
de las decisiones probatorias. Y esta es una cuestión en la que casi nunca se repara.

En efecto, la obligación de motivar la decisión probatoria es el núcleo de la obligación de motivar una decisión. Al margen del estilo de motivación empleado en el laudo, éste debe cumplir con una mínima exigencia de racionalidad justificativa en la valoración de las pruebas; de lo contrario, se abriría paso a la arbitrariedad.

Teóricamente, la valoración probatoria debe seguir dos fases: (i) una valoración individualizada de los medios de prueba; y, luego, (ii) una valoración conjunta de ellas. Esto lo explica Parra:

"El estudio individualizado de cada medio probatorio, las inferencias que se hacen y las reglas de la experiencia que se aplican. Este método de estudio, muestra al justiciable y a la sociedad la manera ponderada y cuidadosa como el funcionario estudia las pruebas. Permite igualmente a las partes observar qué medio de prueba fue mal evaluado, para poder utilizar los recursos. Una vez que se hace el estudio anterior se procede a evaluar las pruebas en conjunto, haciendo una unidad intrínseca19".

En ese mismo sentido, Ferrer Beltrán, afirma lo siguiente:

"Debe advertirse que, si bien una decisión sobre los hechos no puede realizarse sin esa valoración conjunta, ésta no puede ser utilizada para evitar la valoración concreta de cada una de las pruebas aportadas. Es más, solo después de valoradas individualmente las pruebas podrá hacerse con rigor una valoración conjunta de las mismas 20 ".

El convencional proceso de análisis antes descrito no siempre es seguido por los árbitros y, en ciertos casos, hasta es comprensible debido a la complejidad de las materias controvertidas ${ }^{21}$ y al número de escritos y pruebas presentados por las

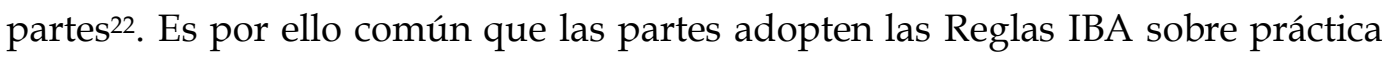
de prueba en el arbitraje internacional. No obstante ello, en determinados laudos

19 PARRA QUIJANO, Jairo. Manual de Derecho Probatorio. Bogotá: Editorial ABC, 2007, p. 7.

20 FERRER BELTRÁN, Jordi. La valoración racional de la prueba. Madrid: Editorial Marcial Pons, 2007, p. 56.

21 Piénsese por ejemplo en los arbitrajes multicontratos. Sobre este tema, Blanco, apunta que: “El arbitraje multicontrato responde a situaciones en las que dos o ma $\square \mathrm{s}$ partes han suscrito una serie de contratos, vinculados por su objeto. Por tanto, una de las diferencias reside precisamente en la existencia de dicho consentimiento expreso por todas las partes involucradas en el arbitraje. Por regla general, este tipo de contratos es propios del sector de la construccio $\square$ n, incluso en sectores donde es ti $\square$ pica la subcontratacio $\square$ n. La intencio $\square$ n con este tipo de arbitraje es, ba $\square$ sicamente, la economi $\square$ a procesal, esto es, resolver arbitrajes basados en $\mathrm{mu} \square$ liples contratos en un mismo procedimiento, ahorrando los costes derivados del mismo. Asimismo, se busca evitar laudos contradictorios dado que, aunque estemos ante contratos distintos, no podemos perder de vista que esta $\square$ n estrechamente relacionados y que existe identidad de objeto".

BLANCO GARCÍA, Ana Isabel. Árbitro y partes: los peligros y entresijos de la práctica del arbitraje. Valencia: Tirant lo blanch, 2020, p. 159.

22 La flexibilidad con la que cuentan los árbitros en materia probatoria es bastante amplia. Por ejemplo, conforme a algunos reglamentos el Tribunal Arbitral tiene la facultad determinar la admisión de una prueba incluso con el laudo final. 
se aprecia un distanciamiento a justificar la decisión probatoria, y esto sí es preocupante. Y muchas veces no solamente es responsabilidad de los árbitros.

Básicamente, un laudo debería plasmar las razones de la prueba preponderante y sus implicancias 23 , así como fijar un listado de pruebas relevantes, justificar porqué son relevantes, brindar un tratamiento especial a la prueba científica o técnica, entre otros aspectos asociados. Si bien es bastante plausible que los árbitros no deban referirse a todas las pruebas practicadas, es indispensable actuar bajo parámetros mínimos de justificación ${ }^{24}$. Y esto porque la técnica del relato en la motivación, que acoge la visión holística o conjunta de la valoración de las pruebas, puede, en ciertos casos, hacer perder de vista una adecuada valoración individualizada de pruebas determinantes en el arbitraje. Recordemos que un buen árbitro maneja técnica probatoria con una apropiada visión de conjunto 25 .

Indiscutiblemente, un laudo no solamente debe plasmar las emociones que deja un caso y el impacto producido en las audiencias (sean presenciales o virtuales ${ }^{26}$ ), lo que se necesita, además, es que los árbitros realicen una valoración profesional de las pruebas y una adecuada justificación de sus decisiones en ese ámbito27. Definitivamente, no es suficiente la "íntima convicción" al momento de decidir cuando se trata de un arbitraje de derecho ${ }^{28}$. Las partes requieren justificaciones concretas y razonadas dentro de un marco lógico proyectado en las pruebas ${ }^{29}$.

23 DE LUIS, J. Félix y ALBUQUERQUE, Nuno. La prueba en el procedimiento arbitral. Pamplona: Thomson Reuters, 2017, pp. 111 y ss.

24 CHOCRÓN GIRALDEZ, Ana. Los principios procesales en el arbitraje. Barcelona: Bosch Editor, 2000, pp. 166-167.

25 ANDERSON, Terence; SCHUM, David y TWINING, William. Análisis de la prueba. Madrid: Marcial Pons, 2015, p. 107.

26 En los últimos años, hemos sido testigos del crecimiento del proceso telemático en las actuaciones arbitrales. El convivio arbitral como obra teatral -esta última por esencia de naturaleza presencial- viene cediendo ante las nuevas exigencias del mercado y del tráfico jurídico.

27 “(...) está empíricamente demostrado que cuanto más complicada es la decisión a tomar, más tendencia existe a acudir a la intuición, básicamente porque el sujeto sabe, en primer lugar, que no puede captar todos los detalles del caso concreto a decidir; en segundo lugar, porque los datos en un contexto complicado suelen ser poco o nada explícitos -como sucede en las situaciones de insuficiencia de la prueba-; y en tercer lugar, porque existe la extendida creencia de que en ese tipo de situaciones, hasta el más pequeño error puede provocar el desacierto de la decisión. Y por ello en este tipo de escenarios el ser humano tiende a confiar ciegamente en los datos que obtiene de su experiencia pasada en ocasiones similares, lo que constituye un atajo para conseguir decisiones acertadas. Pero como ya vimos, ese atajo resulta peligrosísimo, porque conduce a muchos errores. Por ello, existen multitud de trabajos que recomiendan directrices para controlar la intuición en los más diversos ámbitos, hasta el punto de sacar la decisión del terreno de lo inconsciente, llevándola al campo de lo empírico". NIEVA FENOLL, Jordi. La valoración de la prueba. Madrid: Marcial Pons, 2010, p. 206.

28 Ahora bien, claro está que los árbitros tienen total libertad de aplicar en sus decisiones las máximas de experiencia que consideren adecuadas; sin embargo, en esos casos, como bien refiere, Peyrano, se requiere de un mayor esfuerzo discursivo en la motivación. PEYRANO, Jorge. Aproximación a las máximas de experiencia. Su relación con las reglas de la sana crítica. ¿Se trata de dos conceptos disímiles? Prueba I. Santa Fe: Rubinzal-Culzoni editores, 2005, p. 223.

29 ORMAZABAL SÁNCHEZ, Guillermo. El control judicial sobre el fondo del laudo. Madrid: Marcial Pons, 2017, pp. 107 y ss. 
Es por ello que la disyuntiva motivación judicial estricta versus motivación arbitral flexible, a veces se acerca más a un falso dilema, puesto que existe una garantía elemental de motivación racional que tanto jueces como árbitros deben respetar al momento de decidir ${ }^{30}$. No son los mismos estándares, claro está, aunque existen rasgos esenciales de teoría probatoria que bien pueden compartir ambos mecanismos.

Es interesante prima facie revisar algunos conceptos. La doctrina recuerda que históricamente:

"En el Derecho romano existían dos tipos diferentes de sentencias viciadas, distinguiéndose perfectamente entre sentencias contra ius constitutionis y sentencias contra ius litigatoris. Las sentencias contra ius constitutionis, son radicalmente nulas porque el iudicatum del juez supone una contradicción evidente con lo dispuesto en las Constitutiones (...) Por el contrario, las sentencias dadas contra el ius litigatoris, abarcan todos los supuestos de error de hecho y el resto de error de derecho, básicamente errores de subsunción o, más en general, de mal razonamiento de cualesquiera tipos de inferencias que conducen a la decisión. (...) En definitiva, a tenor de lo expuesto, vemos como en el Derecho romano en el caso que nos ocupa, la sentencia dictada con defecto absoluto de motivación, sí que preveía una solución concreta a este asunto. Considerando, a tenor de las disposiciones legales analizadas, que la motivación se convierte en un deber jurídicamente exigible, al menos desde las extraordinariae cognitiones, la falta absoluta de fundamentación de la sentencia romana implicaba la nulidad radical de la misma, precisamente por erigirse directamente contra el ius constitutionis ${ }^{31 "}$.

De ahí que compartamos la idea de Taruffo32, según la cual la justicia procesal es la justicia del procedimiento. La justicia substancial es la justicia de los resultados del procedimiento. El arbitraje es finalmente un procedimiento, con sus propias particularidades, y el grado de calidad y confiabilidad de sus decisiones se

30 Al respecto, Merino y Chillón, advierten que: “En primer lugar, a través de la evolución de la práctica y el Derecho común de los países en que no es exigible la motivación de las sentencias. En Inglaterra es apreciable una tendencia general en el sentido de que determinados jueces y tribunales superiores o administrativos motivan ya sus sentencias. La reforma inglesa de la Ley de Arbitraje de 1979 ha introducido la posibilidad de que los árbitros motiven sus sentencias en determinadas condiciones. Así, si antes de que la sentencia se dicte una de las partes solicita de los árbitros la motivación, la High Court puede pedir al árbitro, una vez que la sentencia ha sido pronunciada, la indicación de los motivos que la han fundamentado. La práctica arbitral ha seguido también los pasos de esta evolución. En Austria y los países nórdicos, en que no es exigible la fundamentación de las sentencias, sin embargo, árbitros e instituciones las motivan de hecho. En Inglaterra mismo, donde para las relaciones del comercio internacional, la no motivación de hecho puediera constituir un serio inconveniente en orden a la ejecución de las sentencias en otro país que considere esta exigencia como de orden público, se ha seguido la práctica de introducir los motivos o fundamentaciones de la sentencia en una hoja aparte, la cual no forma parte técnicamente de la sentencia".

MERINO, José \& CHILLÓN, José. Tratado de Derecho Arbitral. Navarra: Thomson Reuters, 2014, pp. 1663-1664.

31 ALISTE SANTOS, Tomás. La motivación de las resoluciones judiciales. Madrid: Marcial Pons, 2011, pp. $411 \mathrm{y}$ ss.

32 TARUFFO, Michele. Proceso y decisión: Lecciones mexicanas de Derecho Procesal. Madrid: Marcial Pons, 2012, p. 203. 
relaciona inevitablemente con garantías básicas. Sobre el particular, en el libro Proceso y Decisión, el profesor Taruffo aclara lo siguiente:

“Asimismo por lo que se refiere a la corrección del procedimiento, es posible, si bien no siempre fácil, establecer un nivel mínimo por debajo del cual, el proceso no es correcto y, por tanto, falta la condición para obtener una decisión justa. En muchos ordenamientos modernos, dicho nivel se delimita elaborando y especificando las garantías constitucionales del due process of law o de los principios correspondientes de defensa de las partes y de la independencia del órgano jurisdiccional. Otros requisitos, como por ejemplo, la actuación efectiva de la garantía del acceso a los tribunales o del principio de libertad (valoración) de la prueba, son definidos de vez en cuando por la teoría del proceso. Consecuentemente, a pesar de varias dificultades e incertidumbre, es posible imaginar que pueda señalarse un modelo mínimo de proceso justo por debajo del cual puede haber un proceso cualquiera $3^{3 \prime \prime}$.

Bajo ese entendimiento, consideramos que la motivación de la prueba es clave en la justificación de las decisiones. A este propósito es interesante el enfoque del profesor español Joan Picó I Junoy, quien, si bien se refiere a jueces, es factible aplicarlo también a árbitros con algunos matices:

“El derecho a la tutela jurisdiccional efectiva comprende el de obtener una resolución fundada en Derecho que ponga fin al proceso.

Por ello, una aplicación de la legalidad que sea arbitraria, manifiestamente irrazonada o irrazonable no puede considerarse fundada en Derecho. Así ocurre en los casos en los que la sentencia contiene contradicciones internas o errores lógicos que hacen de ella una resolución manifiestamente irrazonable por contradictoria y, en consecuencia, carente de motivación.

Esta obligación de fundamentar las sentencias no puede considerarse cumplida con la mera emisión de una declaración de voluntad del juzgador, en un sentido o en otro, sino que el deber de motivación que la Constitución y la Ley exigen que la decisión esté precedida de la argumentación que la fundamente.

No se trata de exigir a los órganos jurisdiccionales una argumentación extensa, exhaustiva o pormenorizada que vaya respondiendo, punto por punto, a cada una de las alegaciones de las partes, ni impedir la fundamentación concisa o escueta que en cada caso estimen suficiente quienes ejercen la potestad jurisdiccional; se trata de que la tutela judicial efectiva se anude con los extremos sometidos por las partes a debate ${ }^{34 "}$.

En ese orden de ideas, consideramos que la motivación arbitral no puede ser flexibilizada a puntos insospechados, salvo que haya un acuerdo distinto entre

33 Ibid., p. 243.

34 PICÓ I JUNOY, Joan. Las garantías constitucionales del proceso. Barcelona: Bosch Editor, 1997, pp. 60-61. 
las partes ${ }^{35}$.

Es claro que, como lo reconoce el propio autor español recién citado, las decisiones -y aquí incluimos a los laudos- no deben necesariamente contener una justificación pormenorizada y detallada respecto de cada alegación de las partes y de las pruebas aportadas; sin embargo, es menester que exista una motivación racional de las pruebas relevantes, esto es, de las pruebas sobre las que gira la materia controvertida, las cuales deben ser especialmente valoradas y motivadas en el laudo, puesto que son las que determinan el sentido de la decisión (sea de un laudo parcial o de un laudo final). En tal sentido, no es justificable que un Tribunal recurra fórmulas abstractas para aparentar una motivación racional de las pruebas. Al respecto, Picó I Junoy, advierte que:

“No obstante, acerca de la exigencia de valorar motivadamente la prueba desarrollada en el proceso, no podemos desconocer que en la práctica se soslaya continuamente mediante el uso torticero del denominado <apreciación conjunta de las pruebas>, consistente en la declaración del órgano jurisdiccional por la que se limita a manifestar que el material probatorio ha sido valorado <en conjunto> o <conjuntamente>, con omisión de la necesaria justificación racional de las causas por las que se ha concedido validez a los datos fácticos probados en el proceso, esto es, sin la especificación de las fuentes y medios valorados positiva o negativamente por el juzgador ${ }^{36 "}$.

Justamente, para evitar prácticas como la descrita en la cita anterior, es necesario que los árbitros realicen una auténtica valoración de las pruebas que se traduzca en una satisfactoria justificación de las decisiones. No se trata, pues, de que el laudo refleje meras aproximaciones, tanteos o corazonadas probatorias que terminen desnudando ligereza y superficialidad en la labor de valoración.

\section{ii. La mecanización de la prueba y su motivación}

Nos ha tocado apreciar en determinados laudos una recurrencia a una suerte de adivinación. ¿Cómo es eso? Son laudos cuyos puntos resolutivos son claros y precisos, pero nos los motivos que llevaron a tales decisiones. De hecho, existen casos en los que se ganó y no se sabe exactamente las razones de la victoria. Tampoco en el caso inverso. Esto expone al laudo al riesgo de anulación en un país donde hay criterios disímiles en este tópico. Citemos algunos ejemplos de lo que venimos indicando:

a) Posible defecto 1. Se incurre en el prejuicio de confirmación en materia probatoria. Vale decir, los árbitros saben y están convencidos de que alguien tiene la razón y se motiva sólo con el material probatorio de esa parte. Al respecto, Taruffo sostiene lo siguiente:

35 Aun así, resulta válido preguntarse si es constitucional el pacto de no motivación y que tal posibilidad esté permitida por la Ley de Arbitraje.

36 PICÓ I JUNOY, Joan. El derecho a la prueba en el proceso civil. Barcelona: Bosch Editor, 1996, p. 28. 
“De no ser así, caeríamos en lo que los psicólogos definen como el prejuicio de la confirmación según el cual, si yo tengo en mente una hipótesis sobre un hecho determinado, finalmente lo que voy a hacer es una selección entre la información que tengo justo para confirmar mi hipótesis, sin tomar en consideración toda aquella información que está en contraste con mi opinión, esto es, las pruebas contrarias.

Como se verá, ciertamente no se trata de un gran razonamiento, pues al final si no tomo en consideración los argumentos o las pruebas que contradicen mi hipótesis, con toda probabilidad mi razonamiento será erróneo, pues nada excluye que la prueba contraria a lo mejor sea la decisiva ${ }^{37 \prime \prime}$.

b) Posible defecto 2. Se aplica la técnica del story-telling sin pruebas. Es el caso de los laudos que contienen una innumerable repetición de los argumentos de las partes sin mayor referencia a las pruebas. Es más un cuento que una decisión propiamente. Al respecto, Taruffo, puntualiza:

“Los relatos coherentes pero sin sustento no deberían ser tomados en consideración; sólo una historia que, en comparación con otras historias con sustento probatorio, sea relativamente más probable sobre la base de las pruebas relevantes, puede ser apropiadamente elegida como versión verdadera de los hechos en litigio ${ }^{38 "}$.

c) Posible defecto 3. Se aplican los criterios de un jurado y no de un Tribunal de Derecho. En ocasiones es tanta la flexibilidad en la evaluación de los hechos y pruebas, que termina por desnaturalizarse la decisión que debe ser, ante todo, jurídica y, sobre la base de lo debatido y probado por las partes. Así, Taruffo recuerda que:

"Los jurados llegan a sus conclusiones sobre los hechos mediante una evaluación de la plausibilidad de las stories completas acerca de los hechos, sin llevar a cabo ningún razonamiento analítico sobre los hechos específicos o los elementos particulares de prueba. En otras palabras, los jurados estadounidenses determinan la verdad de los hechos de que se trata principalmente mediante la construcción y comparación de stories, más que evaluando críticamente la información aportada por las pruebas ${ }^{39 \prime \prime}$.

La brevísima lista es un elenco de algunas de las falencias que podrían estar incurriéndose en varios arbitrajes y que a veces no son advertidas. Mejorar estos temas ayudaría a crear un mejor clima de atracción arbitral. Y es que, desde nuestra perspectiva, no sólo se trata de modificar normas y de mejorar las prácticas éticas, sino también la labor profesional de quienes participamos en los arbitrajes debe repensarse bajo un prisma propositivo.

37 TARUFFO, Michele. Proceso y decisión: Lecciones mexicanas de Derecho Procesal. Madrid: Marcial Pons, 2012, p. 101.

38 TARUFFO, Michele. La prueba. Madrid: Marcial Pons, 2008, p. 143.

39 TARUFFO, Michele (2007). “Narrativas judiciales”. Consulta realizada el día 21 de julio de 2020. Disponible en: https://scielo.conicyt.cl/pdf/revider/v20n1/art10.pdf 
III. La relevancia de la motivación de la prueba en arbitrajes complejos, como son los arbitrajes de construcción

¿Qué es complex litigation? Los arbitrajes complejos son aquellos en los que la materia en controversia exige determinados conocimientos técnicos y especializados debido a sus particulares métodos, esquemas contractuales, metalenguaje y tamaño de los proyectos involucrados. Los arbitrajes de construcción son un claro ejemplo de ello.

Los abogados desvinculados a dicha especialidad se enfrentan a no pocas barreras: las dinámicas colaborativas, los modelos contractuales, el nivel de detalle técnico es distinto y otra la exigencia, inclusive en materia de negociaciones. Por dar un ejemplo, no es lo mismo un Project Finance convencional que un Construction Project Finance.

En disputas, el Project Delivery System (PDS) es esencial, es decir, el fijado por el propietario de la obra y el que decide qué riesgos retener y trasladar, anclándose su discusión en la correcta o incorrecta elección del PDS y la desviación en la asignación de riesgos. La referida temática es recurrente en este tipo de arbitrajes y su evaluación tiende a ser minuciosa junto a la interpretación de las cláusulas contractuales pactadas en cada caso y la ley aplicable.

En disputas de construcción, las partes pueden, antes que recurrir al arbitraje, intentar resolver sus controversias a través de otros mecanismos, tales como:

i. Neutral evaluation: Un técnico analiza argumentos de las partes y emite una opinión/recomendación no vinculante (propone solución más adecuada).

ii. Adjudication: Un técnico adopta decisión vinculante para las partes, de naturaleza contractual y provisional- interina.

iii. Expert determination: Un técnico emite decisión vinculante que resuelve la controversia de forma definitiva (debate en doctrina si califica o no como laudo)

En los arbitrajes de construcción se requiere, indefectiblemente, de prueba pericial, y esto está vinculado al principio de necesidad de la prueba. ¿Qué es una prueba pericial? Parra, explica sus alcances:

"Cuando en sentido general, en el proceso se requieran conocimientos especializados, es decir, de aquellos que escapa a la cultura de las gentes, puede y debe recurrirse a quienes por sus estudios, experiencia, etcétera, los posean; esos conocimientos pueden ser técnicos, científicos o artísticos. (...) El dictamen pericial es un medio de prueba que consiste en la aportación de ciertos elementos técnicos, científicos o artísticos que la 
persona versada en la materia de que se trate hace para dilucidar la controversia, aporte que requiere de especiales conocimientos ${ }^{40}$.

Particularmente, el nivel de debate de pericias en arbitrajes de construcción es tan intenso, que el Tribunal y las partes pueden recurrir a métodos para delimitar las discrepancias entre los peritos, por ejemplo:

\begin{tabular}{|c|l|}
\hline $\begin{array}{c}\text { "Pre-hearing } \\
\text { meeting" }\end{array}$ & $\begin{array}{l}\text { Celebración de una reunión con los peritos con carácter previo a la ratificación de sus } \\
\text { informes a los efectos de concretar el alcance de éstos y para identificar las cuestiones en } \\
\text { las que los peritos han alcanzado un acuerdo y las cuestiones en las que su opinión técnica } \\
\text { difiere. }\end{array}$ \\
\hline "Hot-tubbing" & $\begin{array}{l}\text { Conocida como 'Conferencia de Expertos', discusión eminentemente sobre cuestiones } \\
\text { técnicas, limitando participación de abogados, en búsqueda de que los peritos realicen } \\
\text { algún tipo de concesión a su contraparte. }\end{array}$ \\
\hline "Scott Schedule" & $\begin{array}{l}\text { Los Árbitros soliciten a los peritos y a las partes que completen un formulario en el que se } \\
\text { identifiquen cada una de las cuestiones técnicas discutidas, los motivos en que cada parte } \\
\text { basa su defensa técnica y los importes en que las partes cifran cada cuestión controvertida. } \\
\text { Se suele utilizar en arbitrajes de construcción (reclamaciones por defectos y retrasos). }\end{array}$ \\
\hline
\end{tabular}

\section{Como afirma Cremades:}

"En definitiva, caminamos hacia la flexibilidad en el tratamiento moderno de la prueba pericial, con mayor objetividad que resulta de los deberes de transparencia y revelación de las circunstancias en las que los expertos realizan su pericia, comunicación entre los propios expertos y la supervisión del tribunal en la presentación de la pericia.

\section{$(\ldots)$}

El arbitraje internacional exige hoy de los peritos que trabajen de forma colegiada más que en régimen de confrontación permanente. Deben ser conscientes de que su función consiste en ayudar al tribunal a tomar una decisión. Por eso, un árbitro experimentado consigue que los peritos de parte trabajen conjuntamente $y$, si no es posible, lo hagan en colaboración con el perito o los peritos designados por el tribunal ${ }^{41 "}$.

En ese contexto, volvamos al tema de la valoración de la prueba y la motivación por parte de los árbitros.

Sobre el particular, el artículo 6.7 de las Reglas IBA sobre Prácticas de Pruebas en el Arbitraje Comercial Internacional, establece que:

“Cualquier Dictamen Pericial emitido por un Perito designado por el Tribunal Arbitral y sus conclusiones serán valorados por el Tribunal Arbitral con la debida consideración de todas las circunstancias del caso".

Así, pues, para que los árbitros puedan lograr convicción, importa que se les dote con instrumentos necesarios para poner a prueba las conclusiones de los peritos.

PARRA QUIJANO, Jairo. Manual de Derecho Probatorio. Bogotá: Editorial ABC, 2007, p. 633.

41 CREMADES, Bernardo. (2014). "Peritaje en el arbitraje internacional". Consulta realizada el día 21 de julio de 2020. Disponible http:/ / www.caic.com.mx/boletines/PERITAJE_EN_EL_ARBITRAJE_INTERNACIONAL_(BC _16012014).pdf 
En ese sentido, existen dos lineamientos generales que consideramos de aplicación al momento de motivar la prueba en este tipo de arbitrajes:

i. Salvo acuerdo de las partes, las evaluaciones periciales deben merecer un pronunciamiento expreso y motivado en el laudo, sea en sentido positivo o negativo ${ }^{42}$.

ii. Para efectos de valoración de prueba científica o técnica, los árbitros deben analizar la fiabilidad de la metodología empleada, su validez y reconocimiento en la comunidad científica.

Lo anterior viene a cuento en la medida que, en el sector construcción son comunes las controversias relativas al expediente técnico, indefiniciones y errores de diseño, ampliaciones de plazo, adicionales, variaciones, backcharges, aprobación y recepción de obra, liquidaciones, disrupciones, sobrecostos, pérdida de productividad y daños vinculados, gerencia del riesgo, rendimientos garantizados, entre otros, que surgen entre comitentes y contratistas. Sin perjuicio de otras temáticas vinculadas como son las pólizas de seguro en contratos de construcción y la coberutra aplicable, las fórmulas compensatorias, las alternativas de restitutio in natura de la infraestructura afectada, la revisión de la ingeniería, el funcionamiento de centrales construidas y otros.

Este tipo de controversias requieren de una especial atención de los árbitros en el manejo de los interrogatorios, de las pericias y en la interacción con los ingenieros y abogados. Estas exigencias especiales se deben reflejar en el laudo, en el que las partes esperan encontrar justificaciones razonadas de las decisiones probatorias. De hecho, los costos periciales en este tipo de casos suelen ser muy altos, debido a que las partes invierten en contratar a firmas reconocidas mundialmente para acreditar los impactos ocasionados en los proyectos de infraestructura en los que intervienen o intervinieron ${ }^{43}$. Fundamentalmente en arbitrajes de obra privada.

42 “La práctica predominante adoptado en el arbitraje internacional es la que sea el tribunal el que proporciona explicaciones razonadas sobre el peso que se ha asignado a los distintos elementos de prueba. Algunos principios que han sido considerados por los tribunales internacionales en su evaluación de la evidencia se exponen a continuación:

i. Al ejercer su facultad de ponderar las pruebas ante ella, el tribunal debe examinar y explicar sus razones para aceptar o rechazar las objeciones formuladas en cuanto a la fiabilidad de una prueba concreta. Esto es cierto sólo si esas pruebas son pertinentes a la adjudicación.

ii. La prueba prima facie es una prueba que puede mantenerse a menos que se cuestiona eficazmente mediante la oposición de pruebas o argumentos.

iii. Un tribunal podrá, a su discreción, conceder un valor determinante a las pruebas circunstanciales.

iv. Un tribunal puede extraer como inferencia adversa la falta de evidencia en el expediente". DE LUIS, J Félix. y ALBUQUERQUE, Nuno. La prueba en el procedimiento arbitral. Pamplona: Thomson Reuters, 2017, p. 106.

43 Si acaso existe un tipo de arbitraje en el que se rompe la presunción de no necesidad de prueba pericial ese es el arbitraje de construcción. Las denominadas "Batallas de Expertos" suelen ser complejas. Cada quien tiene su "verdad" de los hechos. De hecho, en algunos arbitrajes de 
Desafortunadamente, los laudos de construcción no siempre terminan reflejando la calidad de las intervenciones periciales y de las pruebas aportadas; a veces, terminan siendo sólo un relato de las posiciones de las partes y de los peritos, acompañado de una motivación probatoria escasa ${ }^{44}$. En ese aspecto, los arbitrajes ante la Cámara de Comercio Internacional (CCI), por dar un ejemplo, suelen ser más seguros, en tanto existe una preocupación por mejorar la conducción del procedimiento arbitral en esta materia especializada ${ }^{45}$. Desde luego que, comparativamente, son perfectibles algunas prácticas en arbitraje internacional en las que la motivación de decisiones trascendentes es relejada y, en ocasiones, sucinta ${ }^{46}$.

A no dudarlo, las pericias son determinantes para la resolución de las controversias $^{47}$ (l'accertamento tecnico/dichiarazione di scienza ${ }^{48}$ ). De ahí que, tendencialmente, los ordenamientos arbitrales exijan una mayor rigurosidad al trabajo de los peritos en clave de independencia y profesionalismo ${ }^{49}$. En efecto, al ritmo que evoluciona la prueba científica en general 50 , la prueba en arbitrajes de construcción también se moderniza cada vez más ${ }^{51}$ y los actores deben estar a la

construcción se cumple lo que un sector de la doctrina denomina "incontrolada proliferación de pruebas periciales en el arbitraje".

44 Una escasez cualitiativa antes que cuantiativa.

45 Es interesante la regulación sobre los expertos y el rol que desempeñan en los arbitrajes de construcción (Numeral 18: Experts). Véase: ICC COMMISSION REPORT (2019). Construction Industry Arbitrations Recommended. Tools and Techniques for Effective Management. Consulta realizada el dia 21 de julio de 2020. Disponible en: https://iccwbo.org/publication/construction-industry-arbitrations-report-icc-commissionarbitration-adr/

46 No son pocas las veces en las que los árbitros resuelven pedidos relevantes a través de correos electrónicos que sólo contienen la decisión y no los argumentos de justificación. Un ejemplo son los pedidos con ocasión de hechos importantes acaecidos entre la fase de emisión del laudo y la de los pedidos post laudo. Para no avocarse a resolverlos, los árbitros resuelven señalando que se encuentran functus officio.

47 "Los peritos tienen un papel importante en los procedimientos de arbitraje, de modo que el abogado debe asegurarse trabajar mano a mano con ellos. A menudo, debido a los costes implicados, las partes intentan de evitar la contratación de expertos. Esto suele ser un ahorro de costes equivocado. No contratar a un perito en una disputa técnica, o contratar a uno demasiado tarde, a menudo dará lugar a un peor resultado de lo que podría haber logrado con los peritos. Si se necesita un perito, hay que contratar uno temprano e implicarlo en la estrategia del caso. Esto es particularmente importante en el caso de los peritos técnicos, donde el resultado del caso dependerá a menudo de sus conclusiones".

DE LUIS, J Félix. \& ALBUQUERQUE, Nuno. La prueba en el procedimiento arbitral. Pamplona: Thomson Reuters, 2017, p. 96.

48 CAMPIONE, Francesco. La perizia contrattuale. Milano: Giufrrè editore, 2014, pp. 55 y ss.

49 Para mayor referencia: Reglas IBA sobre Representación de Parte (Guidelines Of Party Representation) y Chartered Institute of Arbitrators - Protocol for the Use of Party-Appointed Expert Witnesses in International Arbitration.

50 Por dar un ejemplo, Lafita, resalta la psicología del testimonio, en virtud de la cual un psicólogo especializado en psicología del testimonio acredita la fiabilidad del medio probatorio de la testifical, como una especie de prueba sobre la prueba. Véase: LAFITA SECANILLA, Itziar. "La influencia de la psicología del testimonio en la valoración de la prueba testifical del menor de edad en el proceso civil". En La prueba en acción: Estrategias procesales en materia probatoria. Barcelona: Bosch Editor, 2019, p. 303.

51 Sobre la evolución de la prueba en arbitrajes de construcción, Paredes, sostiene: “La gran limitación temporal que requiere la fuente de prueba para ser idónea en un arbitraje de construcción hace que en muchos casos ni los informes de expertos ni las visitas de los árbitros a obra sean lo suficientemente adecuado para probar una situación producida con mucho 
altura. De ahí que el árbitro no deba circunscribirse a una mera apreciación de las pruebas sino llegar a una efectiva valoración de ellas, sea cual fuere el resultado. $\mathrm{Al}$ respecto, Rivera, sostiene lo siguiente:

“Los conceptos apreciación y valoración no son equivalentes. Apreciación es un concepto más amplio que implica una visión en el contexto general en el cual se interpretan los hechos y su relación con la realidad. El juez [árbitro] tiene que interpretar el resultado de la práctica del medio de prueba, debe formarse un juicio sobre el significado de las declaraciones partes, testigos, expertos-, y de los datos que ofrecen los elementos materiales -documentos, cosas, etc.- La valoración supone la asignación de eficacia probatoria o grado de aporte de conocimiento en el caso concreto con relación a la hipótesis fáctica contenida en la norma que se debe aplicar. El juez [árbitro] tiene el deber de exhaustividad, que significa que debe valorar todos los medios probatorios practicados, dando razón sobre cada uno de ellos. Al no valorar algún medio de prueba, implica que el juez [árbitro] incurre en el vicio que se denomina silencio de prueba, lo cual constituye una infracción de ley de motivación ${ }^{52 "}$.

En efecto, y siguiendo también a Chamorro53, la motivación permite que las partes conozcan las razones de la decisión para intentar eliminar cualquier sensación de arbitrariedad y establecer la razonabilidad de lo que se resuelve. Esto aplica perfectamente a la motivación de las decisiones probatorias.

\section{i. La casuística nos aclara un poco el panorama actual}

Está siendo tendencia que en arbitrajes de construcción los árbitros invoquen el artículo 1332 del Código Civil54 que permite la utilización del criterio de

tiempo de anterioridad, incluso cuando las condiciones o circunstancias que rodeaban los hechos desaparecieron. Esto es lo que agrega dificultad a esta clase de reclamos, convirtiendo en algunos casos al arbitraje en una mera competencia de argumentaciones. En un futuro ya hoy muy cercano, el aporte de la tecnología en el modelamiento de la información para la construcción marcará un hito muy importante para todos los actores de proyectos (es especial, los abogados) obligados a leer o utilizar plataformas colaborativas como el Building Information Modeling (BIM) como fuente de prueba primaria del registro contemporáneo y trazabilidad de la obra en 3D y hasta $8 \mathrm{D}$, superando así el registro manual o escrito. (...) La utilización de esta plataforma se información inteligente orientará una actividad probatoria dirigida a hacer simple lo complejo; es decir, a simplificar la información y análisis crítico: el registro de la data contemporánea y la visualización de cómo se comportó la obra durante su ejecución, facilitará la confrontación de la prueba con cada uno de los eventos que impactaron en el plazo, precio y calidad de la obra. Esta muestra virtual del comportamiento de una obra impactada en el tiempo, colocará a los árbitros en un estadío muy cercano a la contemporaneidad de los hechos y con ello se hará más predecible una decisión final no solo con la realidad contractual sino también con la realidad técnica".

PAREDES CARBAJAL, Gustavo. “El BIM se pone el overall y encima la toga: La tecnología y el cambio en la gestión de las disputas en construcción". En Revista de Derecho Sociedad Jurídica, Vol. 6, 2019, pp. 141 y ss.

52 RIVERA MORALES, Rodrigo. La prueba: Un análisis racional y práctico. Madrid: Marcial Pons, 2011, p. 162.

53 CHAMORRO BERNAL, Francisco. La tutela judicial efectiva. Barcelona: Bosch editor, 1994, p. 205.

54 "Artículo $1332^{\circ}$ del Código Civil.-

Si el resarcimiento del daño no pudiera ser probado en su monto preciso, deberá fijarlo el juez con valoración equitativa." 
valoración equitativa para el cálculo de los daños, estrechamente vinculado con la carga de la prueba. Paradójicamente, la invocación de dicha figura es aplicada para sustituir la obligación de motivar las decisiones probatorias. Así, por ejemplo, en no pocos casos los árbitros señalan que, ante el incumplimiento de una de las partes que afectó el avance de la obra e incrementó los costos de su contraparte, corresponde reconocer el $50 \%$ del monto reclamado por concepto de improductividad de la mano de obra. ¿Cómo llega el Tribunal Arbitral a esa conclusión? Pues, señalando que esa fórmula es la más "razonable" y "equitativa". Una especie de mandato "salomónico" que en realidad es una petición de principio, una falacia.

Otro ejemplo son las reducciones porcentuales sin justificación. Frente a una pericia internacional que establece un monto indemnizatorio en base a un método (fiable y reconocido), el Tribunal Arbitral invoca el criterio de la "cautela" para reducir el monto en 20\%, 30\% o 40\%. ¿En base a qué razonamiento? Ninguno en especial. Incluso, existen laudos en los que a criterio absolutamente discrecional se divide a la mitad los montos por daño emergente y lucro cesante, y eso se ordena como condena dineraria en el laudo. Sin mayores justificaciones.

En otros casos, los árbitros alteran el método pericial empleado y "crean" uno propio sin ninguna base técnica o científica y la exponen en el laudo sin debate previo. Otra irregularidad.

En otros casos ya directamente los árbitros ponen en duda los métodos reconocidos mundialmente para análisis de pérdida de productividad, cuantificación de daños y cuantificación de impactos en plazos y costos, como si fueran meros snobismos jurídicos.

Los métodos aplicados por las firmas internacionales encargadas de calcular los montos de compensación e indemnización son reconocidos científicamente ${ }^{55}$; las partes realizan un esfuerzo por contratar a estos profesionales ${ }^{56}$, lo cual debería traducirse en laudos que reflejen una apropiada valoración de las pruebas y una justificación racional de las decisiones.

Desde luego, ningún reglamento arbitral y tampoco la teoría probatoria exige a los árbitros a ajustarse fielmente a los resultados de un análisis pericial. Los árbitros tienen libertad de valorar las pruebas científicas o técnicas de la manera que mejor consideren apropiada; sin embargo, en los casos en que una pericia cause convicción de manera prevalente, se tiene que justificar porqué esa preferencia y porqué la pericia de la contraparte no es plausible. Existe, en este

55 Véase, por ejemplo, el método Measured Mile para efectos del cálculo de la pérdida de productividad.

56 En algunos casos, se recurre al financiamiento externo para el planteamiento del reclamo arbitral (Third-party funding). 
aspecto, también un deber de motivación por parte de los arbitros en la valoración de la prueba científica o técnica ${ }^{57}$.

En otros casos, es alarmante apreciar que se evita todo intento de valoración probatoria de los métodos internacionales apelando a formalismos contractuales y procesales excesivos que concluyen en laudos inhibitorios, luego de haber transitado por un amplio debate probatorio y técnico, en claro perjuicio en costo y plazo para las partes.

Todo esto sin mencionar los laudos sin motivación que desde hace un tiempo vienen siendo anulados por la justicia comercial y que, según algunas decisiones $^{58}$, coadyuvarían al mejoramiento del laudo en segunda revisión ${ }^{59}$, básicamente en casos de absoluta ausencia de valoración de prueba esencial que son los más insólitos ${ }^{60}$. Felizmente es un porcentaje marginal el de los laudos anulados; sin embargo, tampoco podemos consentir que ese número se acreciente con decisiones probatorias inmotivadas.

En pocas palabras, es necesario repensar la labor en la motivación arbitral de la prueba. No todo es flexibilidad. Si buscamos que el arbitraje ofrezca especialidad y mayor predictibilidad como pilares esenciales de su preferencia, es

57 Al respecto, Simons, sostiene que: “El juez o árbitro no tiene por función sustituir al experto o perito, o pretender convertirse en un científico improvisado. Esto puede traer como consecuencia, que se asuma de manera pasiva o sumisa el dictamen pericial, trasladando casi literalmente su contenido o conclusiones, para sustentar una decisión sobre determinados hechos invocados por las partes. La labor del juez o del árbitro debe ser distinta. Consiste en controlar el trabajo del experto para verificar la credibilidad y la validez del resultado que proporciona al proceso la prueba científica o técnica".

SIMONS PINO, Adrián. "La prueba científica". En Themis Revista de Derecho, núm. 71, 2017, pp. 209-226.

58 Por dar algunos ejemplos, las sentencias de anulación recaídas en los expedientes No 155-2012 (2da Sala Comercial de Lima) y No 130-2015 (1ra Sala Comercial de Lima).

59 Es de considerar válida la posibilidad, no contemplada actualmente en norma expresa, de que luego de la anulación del laudo, no sea el mismo Tribunal el que vuelva a emitir el laudo. Esa es una práctica atendible, por ejemplo, en arbitrajes CIADI. Al respecto, la doctrina señala que: “En adición, y mucho más afín a nosotros, nos encontramos con el Centro Internacional de Arreglo de Diferencias Relativas a Inversiones, mejor conocido como el CIADI, cuyas reglas disponen la posibilidad de interpretar, revisar y anular el laudo por medio de un Comité de Anulación; las reglas CIADI no permiten acudir a reclamar la nulidad antes las autoridades jurisdiccionales. ¿Cómo funciona? La parte insatisfecha pedirá la nulidad del laudo ante el propio CIADI, quien por medio del Comité de Anulación resolverá el recurso, si el laudo es anulado, cualquiera de las partes puede pedir que la disputa sea conocida y resuelta por un nuevo tribunal, quien dictará un nuevo laudo".

HULBERT Andrea. "La nulidad del Laudo en el Arbitraje Internacional". Pragma International network of law and consulting firms. Consulta realizada el dia 21 de julio de 2020. Disponible en: https://pragma.international/article/la-nulidad-del-laudo-en-el-arbitrajeinternacional

60 “Así las cosas, entre el sistema arbitral y el Poder Judicial debe existir una colaboración recíproca de manera que ambos trabajen para realizar una obra y lograr un fin común. Esa obra y fin es que los justiciables puedan acceder a la justicia sustantiva mediante la elección de un mecanismo de resolución de controversias que propicie razonamientos no formalistas, ni extremadamente positivistas, sino razonamientos que, antes que preferir los aspectos materiales de la realidad, integren o amalgamen los hechos con el Derecho en laudos arbitrales casuísticos".

DÍAZ-CANDIA, Hernando. El correcto funcionamiento expansivo del arbitraje. Con especial referencia a la aceptación del arbitraje contencioso-administrativo. Pamplona: Thomson Reuters, 2011, p. 159. 
imprescindible que los árbitros realicen un esfuerzo por entender el lenguaje técnico de las controversias, el impacto de los incumplimientos y los especiales métodos de cuantificación de daños. Esa labor de aprendizaje tiene que ser una obligación a la que los árbitros estén dispuestos a cumplir a fin de arribar a una decisión más ajustada a derecho, esto es, ajustada a lo debatido jurídicamente por las partes y a lo debatido técnicamente.

En esa orientación, es también importante examinar la labor de los abogados, puesto que muchas veces se considera suficiente acreditar el evento de incumplimiento y la responsabilidad civil, y se relega a un segundo plano la acreditación del quantum, pretendiendo persuadir a los árbitros del monto reclamado solamente con la presentación de las pericias y la sustentación de los peritos. Evidentemente esto no colabora a la emisión de un laudo motivado, puesto que ello forzará a los árbitros a adoptar cuestionables fórmulas de fundamentación. En ese sentido, los abogados tenemos que ser el puente entre los peritos y los árbitros para explicar de la manera más didáctica posible los aspectos técnicos de la controversia, su relevancia e impacto.

De modo tal que, en la obligación de motivar las decisiones probatorias, la defensa técnica de las partes tiene también una obligación de desarrollar una coherente y razonada explicación de las metodologías empleadas para calcular la cuantificación de los daños. De ahí que cobra relevancia especial el principio de colaboración en el ámbito del arbitraje, específicamente en la carga del esclarecimiento de los hechos y las pruebas.

En el sector construcción existe a nivel global una tendencia a que los conflictos sean solucionados, preferentemente, a través de: (i) Negociación, (ii) Mediación, (iii) Adjudication y (iv) Dispute Boards. En ese orden de prevalencia61.

En el Perú, el sector construcción soluciona preferentemente sus conflictos a través de Arbitraje y, en un segundo escalafón, a través de los Dispute Boards.

Con ese panorama, el arbitraje local adquiere un deber mayor de mejorar sus técnicas de valoración probatoria y mejorar sus estándares de motivación, si no se quiere desincentivar a los jugadores del sector a preferir otros métodos de solución ${ }^{62}$ en los que puedan ser técnicamente mejor entendidos y en los que se prodiguen soluciones más justas con las pruebas con las que se cuenta.

\section{Consecuencias de la inadecuada utilización de la motivación de la prueba}

Salvo en los casos que se pacta resolver en equidad o conciencia, los arbitrajes de

61 Esta data puede ser corroborada en: Arcadis (2019). Global Construction Disputes Report 2019. Consulta realizada el dia 21 de julio de 2020. Disponible en: https://www.ciarb.org/news/arcadis-global-construction-disputes-report-2019/

62 THOMSON, Dean \& Paul LURIE. “The Guided Choice Process for Early Dispute Resolution”. En The American Journal of Construction Arbitration \& ADR, Vol. 1, N 1, 2017, pp. 23 y ss. 
derecho tienen que resolverse a través de laudos con una debida motivación de las decisiones probatorias. De modo que la utilización de la "equidad" y la "cautela", como fórmulas que reemplazan a la valoración de las pruebas técnicas aportadas al proceso, constituye una arbitrariedad manifiesta63.

De hecho, la equidad regulada en el artículo 1332 del Código Civil, de influencia italiana, está pensada para casos en los que la cuantificación del daño es muy difícil, por ejemplo, los casos de fijación del quantum indemnizatorio derivada de la pérdida de chance o del daño moral. Fundamentalmente, es una figura aplicable para daños no patrimoniales.

En los casos en los que exista una diligencia probatoria de las partes y elementos técnicos suficientes, es primordial que los árbitros motiven sus decisiones sobre la base de métodos y no sobre la base de criterios genéricos. Al respecto, el profesor Taruffo, afirma lo siguiente:

“[El juzgador] debe ser consciente de los límites (y también de las lagunas) de su cultura no jurídica, y debe ceder el espacio al científico siempre que un hecho pueda $-\mathrm{y}$, por tanto, deba- ser probado mediante métodos científicos. Parece razonable sostener, en efecto, que siempre que se pueda disponer de pruebas científicas éstas resultan preferibles al recurso a nociones no científicas ${ }^{64 "}$.

Incluso, en los arbitrajes de equidad, conforme con lo señalado por De Trazegnies ${ }^{65}$, se exige un razonamiento jurídico básico y necesario para evitar la arbitrariedad. Con mayor razón en arbitrajes tan sofisticados como los arbitrajes de construcción la motivación de la prueba es fundamental.

Por otra parte, no estamos aquí desmereciendo la importancia que tiene el criterio de valoración equitativa al momento de determinar un monto compensatorio y/o indemnizatorio. Es hasta aconsejable recurrir a esta figura legal en casos en los que existe una dificultad real de cálculo del quantum procesal. Lo que no compartimos es que dicha figura reemplace la labor de valoración probatoria de los aspectos técnicos que deben realizar los árbitros.

El estándar de motivación en el arbitraje puede ser menos riguroso, menos exigente, más flexible: aunque sea difícil encontrar a alguien que acepte pactar la

63 "Ni en el plano doctrina, ni en el de la práctica fue necesariamente el arbitrio expresión de mero capricho del juzgador. Su identificación inexorable con la arbitrariedad es rechazable (...) la posición de la doctrina no es contra el arbitrio en sí, sino contra su generalización y mal uso, porque acepta sin reparo que en los casos no determinados por leyes, cánones o doctrinas pueda el juez proceder y sentenciar por su albedrío bien informado y circunspecto, regulándole y considerándole a la manera y traza del juicio legal y según el proceso y por la equidad y derecho y por parecer de los sabios y no por su cerbelo y antojo desviado de la forma, orden y disposición del Derecho".

FERNÁNDEZ, Tomás-Ramón. Arbitrario, arbitraire, arbitrary. Pasado y presente de un adjetivo imprescindible en el discurso jurídico. Madrid: Iustel, 2016, pp. 35-38.

64 TARUFFO, Michele. La prueba. Madrid: Marcial Pons, 2008, p. 279.

65 DE TRAZEGNIES GRANDA, Fernando. “Arbitraje de Derecho y arbitraje de consciencia”. En Revista Ius et Veritas, núm. 12, 1996, pp. 116 y ss. 
arbitrariedad, es decir, que acepte que la decisión que resuelva una controversia no vaya a estar motivada66. Lo cierto es que la motivación es una garantía constitucional y el arbitraje no escapa a tal obligación ${ }^{67}$. ¿Se está cumpliendo ello en los arbitrajes locales en los que se discuten cuestiones técnicas como los arbitrajes de construcción?

Actualmente, algunas empresas optan por elegir centros de arbitraje internacionales para la resolución de sus controversias 68 ; es decir, instituciones que, de algún modo, garanticen una mayor exhaustividad en la valoración de las pruebas y, en general, una mejor calidad de los laudos, en especial, en arbitrajes complejos donde la significancia de lo resuelto impacta en núcleos sensibles de la economía (construcción, hidrocarburos, electricidad, minería, etc.). La idea es buscar formas de reducir los riesgos de arbitrariedad en el proceso arbitral ${ }^{69}$. A eso tiene que apuntar el sistema peruano: a tratar -hoy más que nunca- de mejorar institucionalmente este valiosísimo mecanismo de solución de controversias, reforzando sustancialmente el compromiso por mejorar el nivel de los laudos en cuanto a parámetros mínimos de racionalidad jurídica y motivación de las decisiones probatorias.

Inclusive, debido a los temas antes reseñados, un sector de la doctrina comparada ha llegado a pretender procesalizar la labor probatoria de los árbitros. Una práctica errónea, además de exagerada. Así, Ormazabal, sostiene que:

66 Esos pactos de no motivación, sin embargo, existen, no caben dudas. No puede desconocerse esa realidad, sobre todo en praxis arbitral foránea.

67 Nuestro Tribunal Constitucional en los Precedentes 6167-2005-PHC/TC y 142-2011-AA/TC, ha establecido que el arbitraje al ser función jurisdiccional está sometido a control constitucional, porque no existe zona exenta de tal control. Es por ello que, la Ley de Arbitraje en su Duodécima Disposición Complementaria y Final ha dispuesto que el recurso de anulación de laudo es una vía específica e idónea para proteger cualquier derecho constitucional. De manera que los árbitros también están sometidos a la Constitución y a la aplicación de los estándares de garantías contenidos en los tratados, como es el caso de los artículos 8.1 y 25.1 del Pacto de San José de Costa Rica.

68 En importantes reglamentos arbitrales se establece de que el proyecto de laudo sea sometido previamente a la aprobación por parte de los órganos de la institución administradora, por ejemplo, el artículo $34^{\circ}$ del Reglamento de Arbitraje CCI, establece que: Antes de firmar un laudo, el tribunal arbitral deberá someterlo, en forma de proyecto, a la Corte. Esta podrá ordenar modificaciones de forma y, respetando la libertad de decisión del tribunal arbitral, podrá llamar su atención sobre puntos relacionados con el fondo de la controversia. Ningún laudo podrá ser dictado por el tribunal arbitral antes de haber sido aprobado, en cuanto a su forma, por la Corte.

69 El jurista español, José María Alonso, sostiene que: “Hay que reforzar el papel de las instituciones arbitrales. Tienen que velar por la calidad y honorabilidad de los árbitros que se eligen. La comunidad arbitral tiene que dotarse además de códigos de buenas prácticas muy estrictas donde se contemplen los conflictos de intereses y se establezca la conducta que tienen que tener los abogados y árbitros. También debe incidirse en la transparencia. Hay un cierto oscurantismo en el arbitraje que se pretende justificar con la confidencialidad. Estoy de acuerdo con eso pero hay maneras de que se puedan dar a conocer cuáles son los resultados. Cuando te hablo de corresponsabilidad, por ejemplo, la ley en España hace a las cortes corresponsables con los árbitros en supuestos de mala praxis". Consulta realizada el dia 21 de julio de 2020. Disponible en: https://elcomercio.pe/economia/peru/debemos-sancionar-garbanzos-negrosnoticia-638502-noticia/ 
"En cualquier caso, por mucho que en el procedimiento arbitral no tengan vigencia las normas de la LEC, parece poco discutible que la apreciación de las pruebas por parte de los árbitros debe discurrir también por los cauces de la motivación racional, el sentido común o sana crítica. Estamos ante mucho más que una simple norma rectora del proceso civil, pues entronca con el orden constitucional y, por ende, con el orden público en su vertiente procesal. De ahí que en los supuestos en que la apreciación de la prueba por parte de los árbitros choque de modo evidente, ostensible o palmario con la racionalidad o la sana crítica, el laudo estaría incurriendo en un defecto de motivación que podría justificar su anulación.

De ahí a abominar o repudiar en el procedimiento arbitral toda norma contenida en la ley procesal civil, sin embargo, creo que va un trecho muy considerable. Porque ciertos preceptos de dicha ley no hacen sino recoger, por una parte, verdaderas exigencias de rango constitucional y, por otra, sensatas normas de proceder para dirimir controversias acrisoladas por la experiencia de siglos en la impartición de justicia.

A mi juicio, ese es el carácter que tiene el art. 217 LEC, referido a la distribución de la carga de la prueba, que plasma, al menos en lo esencial y con carácter general, un esquema atributivo similar al de todas las naciones civilizadas $70^{\prime \prime}$.

Lamentablemente, tal delicada interpretación equipara las causales de impugnación de sentencias con las del laudo y, así, acabamos por desnaturalizar al arbitraje ${ }^{71}$, so pretexto de alegar que un laudo es absurdo o ilógico. Al respecto, Rivera, enfatiza lo siguiente:

“En cuanto a la logicidad quizá sea preferible indicar que en ese caso la motivación es absurda o irracional. Esto es, cuando en la sentencia la argumentación de hechos probados, sea por la conexión o interpretación, se quebrantan las leyes de la lógica, del conocimiento científico, el sentido común o las máximas de experiencia; o bien cuando los argumentos jurídicos son incoherentes, o cuando aplicando el silogismo se yerra en las premisas por confusión de los conceptos contenidos en las mismas, o asume alguna como cierta sin serlo, o cuando no se expresa con claridad qué criterios siguió el juzgador para llegar a tal resultado ${ }^{72}$.

Lo descrito precedentemente parte de la idea -errada desde nuestro punto de vista- de equiparar la probática judicial con la probática arbitral. En esa línea, Ormazabal, persiste:

“Que si los árbitros (al menos los que deben resolver según Derecho) ignoran las normas legales reguladoras de la carga de la prueba previstas

70 ORMAZABAL SÁNCHEZ, Guillermo. El control judicial sobre el fondo del laudo. Madrid: Marcial Pons, 2017, pp. 108 y 114.

71 Desnaturalización que se agrava aún si persiste la idea de algunos procesalistas latinoamericanos de confeccionar un proyecto de ley modelo de arbitraje comercial.

72 RIVERA MORALES, Rodrigo. La prueba: Un análisis racional y práctico. Madrid: Marcial Pons, 2011, pp. 421-422. 
en la LEC u otras disposiciones legales, están quebrantando aquella seguridad jurídica o previsibilidad que deben proporcionar las normas que regulan el tráfico jurídico y que el árbitro de Derecho debe aplicar para dictar el laudo.

Pero para que dicha infracción, cometida en un procedimiento arbitral pueda justificar la impugnación del laudo, es preciso que esté contemplada entre los motivos de anulación previstos en el artículo 41.1 LA, cuestión que seguidamente paso a examinar.

En primer lugar, si los árbitros no han hecho una expresa advertencia a las partes en relación con los criterios de atribución de la carga de la prueba diferentes de los legales que pretenden aplicar para dictar el laudo, me parece del todo claro que esta omisión implica vulnerar el derecho de defensa de la parte afectada, pues de este modo se priva de la oportunidad de levantar la carta probatoria que los árbitros <<creativamente >> le endilgan al dictar el laudo, apartándose de los criterios de previsibilidad y seguridad jurídica y lesionando su derecho de defensa ${ }^{73}$ ".

Tales consideraciones provenientes de la teoría procesal pura y dura74, consideramos que no pueden ser transplantadas sin más al arbitraje ${ }^{75}$. Ahora bien, tampoco es válido minimizar los errores de motivación de las decisiones probatorias en arbitrajes complejos que, incluso, por criterios de mala fe de alguna parte y excacervada procesalización del arbitraje pueden terminar siendo anulados cuando debieron ser laudos cuidados $a b$ initio76. Más aún cuando un sector de la doctrina prioriza garantías básicas en la praxis arbitral, así por ejemplo, Oppetit, afirma que:

"El arbitraje ya no puede reducirse a un puro fenómeno contractual, como lo reclaman los apasionados discursos críticos de Merlin: su naturaleza jurisdiccional hoy no es puesta en duda, aunque su origen siga siendo

73 ORMAZABAL SÁNCHEZ, Guillermo. El control judicial sobre el fondo del laudo. Madrid: Marcial Pons, 2017, pp. 116-117.

74 "Supone la acción de anulación el desembarco jurisdiccional en el arbitraje, la garantía irrenunciable de la tutela judicial efectiva, la garantía jurisdiccional de que el Estado no puede desentenderse totalmente del arbitraje, ya que debe ejercer un cierto control del laudo arbitral, funcionando así como termómetro necesario en la búsqueda de un equilibrio entre la flexibilidad que rige en el arbitraje y las garantías en el proceso civil".

BURGOS LADRÓN DE GUEVARA, Juan. Intervención jurisdiccional en el arbitraje. En: Vademécum de principios inspiradores del arbitraje y de práctica arbitral de tribunales arbitrales según la nueva ley de arbitraje 60/2003. San Sebastián: Instituto Vasco de Derecho Procesal, 2005, pp. 72-73.

75 El jurista Jorge Santistevan de Noriega, sostenía que entre el proceso y el arbitraje existe una vecindad: Asi, para este autor: "La vecindad, entonces, no necesariamente supone cercanía, menos sobreposición de territorios, pero tampoco entraña enemistad".

SANTISTEVAN DE NORIEGA, Jorge. “Arbitraje y proceso civil, ¿vecinos distantes?: el debido proceso en sede arbitral". En Revista Ius et Veritas, núm. 37, 2008, p. 58.

76 “En definitiva, la perspectiva de una acción de anulación y, por tanto, de una judicialización de la controversia, puede ser un escenario indeseable para las partes quienes probablemente hayan sometido sus controversias a arbitraje a fin de evitar los inconvenientes que pudiera presentarles la solución judicial. Por este motivo, no resultaría extraño que las partes acordaran renunciar o negarse mutuamente la posibilidad de interponer una futura acción de anulación contra el laudo".

RIPOL, Ignacio. La ejecución del laudo y su anulación. Estudio del artículo 45 LA. Barcelona: Bosh Editor, 2013, p. 101. 
contractual; el arbitraje es una justicia privada, es cierto, pero una justicia al fin y al cabo: ésta proviene de la voluntad de las partes de confiar a un tercero el poder de juzgar: el árbitro se ve investido de la $<<$ jurisdictio $>>$ en toda su plenitud, con la flexibilidad que autoriza el marco dentro del que es ejercida; este marco procesal se parece cada vez más al de los tribunales estatales, en virtud de un proceso habitual a toda institución: desde el instante en que el arbitraje afirma ofrecer a las partes las garantías inherentes a toda justicia, encuentra él mismo, en virtud de una evolución natural (y no solamente en el arbitraje internacional), así sea en formas adaptadas a sus propias exigencias, los imperativos de organización y de funcionamiento que imponen a toda jurisdicción, cualquiera que ésta sea $^{77 "}$.

En general, la motivación como garantía constitucional y la motivación de las decisiones probatorias en particular, son exigibles bajo un esencial orden jurídico arbitral, tanto más en arbitrajes complejos como son los arbitrajes de construcción.

\section{Comentario Final}

Con miras a que el arbitraje local se consolide, consideramos que se deben fortalecer no solamente las prácticas éticas 78 ; también se debe perfeccionar la técnica de motivación de las decisiones probatorias, con la finalidad de mejorar la calidad de los laudos y que cada vez sean menos susceptibles de anulación. El problema no solamente es porqué el Poder Judicial anula determinados laudos por defectos de motivación; la cuestión es si realmente esos laudos contienen una adecuada motivación probatoria que los aleje de la arbitrariedad ${ }^{79}$. En tal sentido, en la comunidad arbitral tenemos una cuota de responsabilidad en mejorar ética ${ }^{80} \mathrm{y}$ técnicamente ${ }^{81}$ la calidad de los laudos.

77 OPPETIT, Bruno. Teoría del Arbitraje. Colombia: Legis Editores, 2006, pp. 57-58.

78 “(...) en relación al alcance de la inmunidad del árbitro, la diferencia entre los países del civil law y aquéllos del common law se acentúa en lo relativo a la inmunidad del juez. Si bien los primeros reconocen cierta inmunidad al árbitro dentro del ejercicio de sus funciones, los segundos lo protegen aún mucho más".

CLAY, Thomas. El Árbitro. Bogotá: Grupo editorial Ibañez, 2012, p. 95.

79 Consideramos que la regla es similar a la imparcialidad. No solamente el árbitro debe ser imparcial sino también parecerlo. El laudo igual: no solo debe dar la sensación de estar motivado (por ejemplo, con páginas innumerables) sino parecer que lo está en sus fundamentos.

80 Es materia de debate actual la impugnación del laudo por fraude procesal. Tema de suma relevancia sobre la cual se esperan mejores iniciativas legislativas. La doctrina viene perfilando hace varios años interesantes aproximaxiones. Léase, por ejemplo: CARRILLO ZAMORA, Mercedes. La impugnación internacional de la sentencia arbitral por fraude procesal. Cádiz: Servicio de publicaciones de la Universidad de Cádiz, 2011, pp. 83 y ss.

81 El proceso es un instrumento técnico y ético. Ambos van de la mano. Mejorar en ambos aspectos es clave para evitar críticas severas al sistema arbitral. Véase, por ejemplo: MONROY GÁLVEZ, Juan F. "El cuarto de siglo del CPC. ¿Algo que celebrar? No, apenas para recordar". En Revista Jurídica del Diario El Peruano, 2018, p. 5. 